www.jmscr.igmpublication.org

Impact Factor 3.79

Index Copernicus Value: 5.88

ISSN (e)-2347-176x ISSN (p) 2455-0450

crossref DOI:_http://dx.doi.org/10.18535/jmscr/v4i02.34

\title{
Outcome Measures of Psoriasis in Clinical Trials: An Overview
}

\author{
Authors \\ Satyapal Singh $^{1^{*}}$, Rajendra Prasad ${ }^{2}$, J.S. Tripathi ${ }^{3}$, N.P. Rai ${ }^{4}$ \\ ${ }^{1}$ Research Scholar, ${ }^{2}$ Associate Professor, ${ }^{3}$ Professor \& Head, ${ }^{4}$ Professor \& Supervisor \\ Department of Kayachikitsa, Faculty of Ayurveda, Institute of Medical Sciences, \\ Banaras Hindu University, Varanasi, Uttar Pradesh, India \\ *Corresponding Author \\ Satyapal Singh
}

Research Scholar, Dept of Kayachikitsa, Faculty of Ayurveda, Institute of Medical Sciences

Banaras Hindu University, Varanasi, Uttar Pradesh, India

Email: spmairti@gmail.com,Mo.09450035793

\begin{abstract}
Psoriasis is a common chronic inflammatory dermatological disorder resulting from interactions between genetic pre-disposition and triggering environmental factors. It affects approximately 1-3\% of the population and poses a lifelong burden on those, affected. Psoriasis typically follows a relapsing and remitting course. It can occur at any age, although is uncommon in children (0.71\%) but the majority of cases occur before 35 years. Psoriasis is associated with arthritis in a significant proportion of patients (reported in one study at 13.8\%). Usually the psoriasis is not life threatening but it can be life ruining due to its visibility. In clinical trials, several outcome measures have been used to assess the severity of psoriasis. The common outcome measures include PASI (psoriasis area and severity index) score, Psoriasis Life Stress Inventory (PLSI), Psoriasis disability index (PDI), The National Psoriasis Foundation Psoriasis Score (NPF-PS), Physician Global Assessment (PGA), Self-Administered PASI (SAPASI), Simplified PASI (SPASI), Psoriasis Assessment Severity Score (PASS), Psoriasis Log-Based Area and Severity Index (PLASI), Psoriasis Exact Area and Severity Index (PEASI) and Beer Sheva Psoriasis Severity Score (BPSS). Among these, the PASI score is most popular and commonly used in clinical trials. To assess the quality of life in the patients of psoriasis the DLQI (dermatologic life quality index) is most commonly used in clinical trials.

Several such instruments have been developed and continue to be developed to provide an assessment of the severity of the skin lesions. Since the skin lesions of psoriasis have an impact on quality of life of patients, there has been growing recognition of the need to measure the impact of the disease on quality of life along with the severity of the lesions.
\end{abstract}

KEYWORDS: Psoriasis, outcome measures, PASI, DLQI, Quality of life.

\section{INTRODUCTION}

Psoriasis is a systemic chronic, relapsing inflammatory skin disorder with worldwide distribution, affecting $1-3 \%$ of the world population. Prevalence varies according to race, geographic location and environmental factors ${ }^{[1]}$. The disease has wide clinical spectra that range from epidermal (scaly) and vascular (thickened, erythematous) involvements of the skin to the 
malignant form known as generalized erythrodermia.

Several epidemiological and clinical studies have confirmed that psoriasis is associated with many co-morbid conditions which include, arthritis, cardio-metabolic disorders including myocardial infarction, stroke, diabetes, obesity, dyslipidemia and non-alcoholic fatty liver disease. These comorbidities confer a higher mortality rate. The presence of any co-morbid diseases worsens the psoriasis and also associated with an increase in concomitant medication ${ }^{[2]}$. Psoriasis can have profound effects on patients' daily living and functioning ${ }^{[3,4]}$.

During measurements of clinical severity, separately using tools such as the Psoriasis Area and Severity Index (PASI) ${ }^{[5]}$ are not sufficient and may not reflect patients' own perceptions of the impairment due to psoriasis, it is important to assess the impact of psoriasis on patients' physical condition, self-perception, and social life ${ }^{[6,7]}$. Health Related Quality of Life (HRQOL), covering almost all these parameters, is therefore increasingly part of the clinical research and practice. HRQOL assessment can provide valuable information that helps to make clinical decision and to select suitable health care programmes ${ }^{[8]}$. There has been a wide variety of generic, dermatological and psoriasis-specific instruments used for the assessment of HRQOL of psoriasis patients ${ }^{[9-11]}$. However, the reliability and validity of these instruments are not fully known ${ }^{[12-13]}$. The reliability and validity are the major evaluations of instrument's performance for reflecting concepts or ideas such as quality of life (QOL) in a study population ${ }^{[14]}$. Evaluating the characteristics of instruments used to measure patient's perceptions is important in clinical health care and decision making.

For most people, psoriasis is managed in primary care, with specialist referral being needed at some point for up to $60 \%$ of people. Supra-specialist (level 4) tertiary care is required in the very small minority with especially complex, treatment resistant and/or rare manifestations of psoriasis [15].

Good communication between healthcare professionals and patients is essential. It should be supported by evidence-based written information tailored to the patient's needs. Treatment and care and the information given by patient about it, should be culturally appropriate. It should also be accessible to people with additional needs such as physical, sensory or learning disabilities, and to people who do not speak or read English.

Adult and pediatric healthcare teams should work jointly to provide assessment and services to young people with psoriasis. Diagnosis and management should be reviewed throughout the transition process, and there should be clarity about who is the lead clinician to ensure continuity of care.

\section{OUTCOME MEASURES}

Several instruments have been described to assess psoriasis severity in recent years, such as PASI (psoriasis area and severity index) score, Dermatology Life Quality Index, Physician's Global Assessment, Psoriasis Disability Index, Psoriasis Life Stress Inventory, and the Salford Psoriasis Index, etc. ${ }^{[16-21]}$.

A clinician should have to assess the impact of disease on physical, psychological and social wellbeing, psoriatic arthritis and other comorbidities. In non-specialist clinical setting the patient should be refer to dermatologist if there is uncertainty of diagnosis, severe or extensive psoriasis (for example more than $10 \%$ of the body surface area is affected), topical therapy fails to control the psoriasis, nail disease has a major functional or cosmetic impact and Psoriasis is having a major impact on a person's physical, psychological or social wellbeing ${ }^{[22]}$.

When assessing the disease severity in any healthcare setting, there should be proper recording of the body surface area affected, any involvement of nails, high-impact and difficult-totreat sites (for example, the face, scalp, palms, soles, flexures and genitals), systemic upset such 
as fever and malaise, etc. and in specialist settings, use a validated tool to assess severity of psoriasis, for example the Psoriasis Area and Severity Index (PASI) ${ }^{[23]}$.

In specialist settings, use a validated tool to assess the impact of any types of psoriasis on physical, psychological and social wellbeing, for example the, Dermatology Life Quality Index (DLQI) for adults or Children's Dermatology Life Quality Index (CDLQI) for children and young people. When using an assessment tool for a person with any type of psoriasis take account of their age, any disabilities (such as physical, visual or cognitive impairment), and any language or other communication difficulties, and provide help and support if needed. Ensure that the chosen assessment tool continues to be a sufficiently accurate measure. In children, young people and adults with psoriasis new tools can be developed and/or existing ones further refined and validated to Assess disease severity and impact in both nonspecialist and specialist healthcare settings to facilitate assessment, appropriate referral, treatment planning and measurement of outcomes.

\section{Importance of Assessment}

Assessment of disease severity and impact is fundamental to delivering high-quality health care and measuring outcomes. The evidence review indicates that the existing tools have important limitations, and have not been validated in relevant healthcare settings or in children or young people. Future research should ensure that such type of tools will be developed that capture information on site of involvement as well as extent and the impact of previous treatments. Tools should capture all aspects of impact on life including physical, psychological and social wellbeing and factors that may influence this impact, such as distress and beliefs about psoriasis. Tools that can be used by patients as well as by healthcare professionals to assess disease severity and that encompass new technologies should be evaluated to facilitate (when appropriate) modern healthcare delivery models like remote monitoring of disease activity. In addition, understanding the true burden and effect of disease activity, severity and impact for both psoriasis and psoriatic arthritis has not previously been comprehensively studied. Capturing this information and distilling out significant factors for focused investigation will lead to better understanding of the needs of this particular group of people and the impact of treatments that benefit both disease compartments i.e. skin and joints.

\section{PASI (Psoriasis Area and Severity Index)}

PASI was developed to assess the effects of retinoids in psoriasis by Fredriksson $\mathrm{T}$ and Pettersson U in $1978^{\text {[24] }}$. Clinical assessment of psoriasis severity was done at base line and at the end of the treatment period using PASI ${ }^{[25]}$.

Four affected anatomical sites, the head (h), upper limb (u), trunk (t) and lower limbs (l), are separately scored by using three parameters, erythema, induration and desquamation/scaling, each of which is graded on a severity scale of 0 to 4 , where $0=$ nil, $1=$ mild, $2=$ moderate, $3=$ severe and $4=$ very severe. The area-wise percentage involvement of the involved sites is calculated as: $1=$ less than $10 \%$ area; $2=10$ $29 \% ; 3=30-49 \% ; 4=50-69 \% ; 5=70-89 \%$; and $6=90-100 \%$. The head, the trunk, the upper extremities, and the lower extremities correspond to $10 \%, 20 \%, 30 \%$, and $40 \%$ of the total body area, respectively ${ }^{[26]}$.

\section{Calculation of PASI}

The PASI score is calculated by following formula

PASI $=0.1\left(E_{h}+S_{h}+I_{h}\right) A_{h}+0.2\left(E_{u}+S_{u}+I_{u}\right)$ $A_{u}+0.3\left(E_{t}+S_{t}+I_{t}\right) A_{t}+0.4\left(E_{1}+S_{1}+I_{1}\right) A_{l}$

The affected area and lesion characteristics are entered in a formula that results in a score from 0 to 72. The PASI is most often used in clinical trials. The maximum score of PASI is 72. PASI 75 is a $75 \%$ reduction of baseline PASI score. It is commonly considered as a denominator for 
satisfactory results of any treatment modality for psoriasis $^{[27]}$.

The Psoriasis Area and Severity Index has widely used and serves as a surrogate for a gold standard for the assessment of psoriasis severity. However, the PASI has several drawbacks that prevent it from becoming a practical clinical instrument for routine clinical use. It does not consider involvement of the face, palms and soles, or the genital area. Even mild involvement in these locations may greatly affect the patient's suffering but is under estimated in the total PASI score. Moreover, PASI does not include quality of life parameters ${ }^{[28-31]}$. The PASI score is too long to perform and therefore impractical for routine clinical use. The need for a new instrument to assess psoriasis severity for both research and routine clinical use is widely recognized in the dermatological world ${ }^{[32-33]}$.

\section{PASI and Clinical Trials}

Improvement in this score in clinical trials is presented as a percent improvement over the baseline score. Patients who experience a $75 \%$ improvement in their PASI scores after treatment (e.g from a score of 20 to 5) are said to have achieved PASI 75.

For most clinical trials, the number of patients on the study drug achieving PASI 75 is the primary efficacy measure. In terms of clinical improvement, a PASI 75 improvement correlates well with a physician global assessment (PGA) of clear to almost clear.

There is also an excellent correlation with statistically significant improvement in the patient's quality of life.

\section{Limitations of PASI}

- In everyday practice, the ultimate goal regarding psoriasis treatment outcome is patient quality of life not Psoriasis Area Severity Index (PASI) improvement. What one patient perceives as success another patient may consider an unacceptable amount of improvement.
- Clinical trials use PASI 75 and PASI 50 as bench marks for improvement. Some drugs have PASI 90 data, which is even more impressive. But, if you consider the myriad of different presentations psoriasis may have in any given patient or in the population as a whole, initial PASI scores cannot adequately capture the severity of the disease in all patients. For example, patients with palmo-plantar psoriasis, which affects approximately $4 \%$ body surface area (BSA), will have a low PASI score since PASI scores are weighted by the extent of area of involved as well as the severity of the erythema, induration and scaling in that area. Despite these low PASI scores, patients suffering from palmo-plantar psoriasis typically have very low quality of life (QOL).

- The low PASI scores do not correctly correspond to quality of life for these patients. These patients may not be able to walk, conduct business, or function in society due to the visible nature of their disease.

Moreover, PASI is the most widely used measure of severity in the researches as well as in the clinical setting. This makes it an important tool in gauging the impact of the disease on QOL, though other instruments to measure QOL are encouraged. Since PASI or SAPASI do not measure the impact of psoriasis on patient's QOL directly, use of other QOL scales is recommended [34].

\section{DLQI (Dermatology Life Quality Index)}

DLQI, developed by Finlay and Khan in 1994, was the first tool of QOL evaluation related to dermatology ${ }^{[35]}$. It developed according to the principles of classical test theory as a skin disease specific instrument to assess HRQOL. It consists often items, which estimate disease influence regarding: symptoms and feelings, daily activities, leisure, work, school, personal relationships and treatment. Due to its easy application and the 


\section{JMSCR Vol||4||Issue||02||Page 9298-9311||February}

increasing importance of HRQOL in the evaluation of clinical studies, the DLQI became the most commonly used HRQOL measure in dermatology ${ }^{[36-37]}$. The aim of this questionnaire

Table.1. Tabular presentation of questionnaire and outcome score to assess the DLQI. Modified from ${ }^{[38]}$.

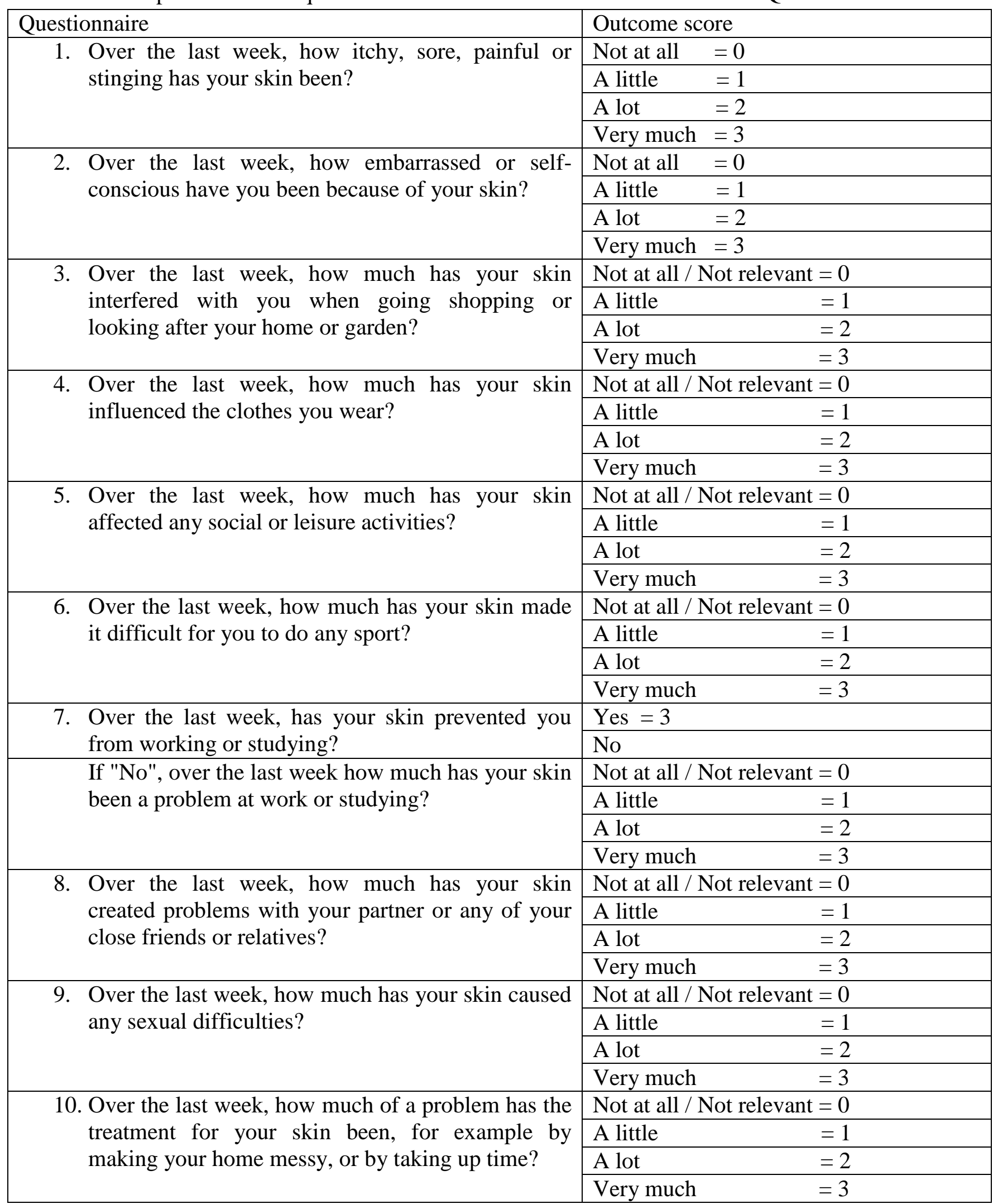

is to measure how much your skin problem has affected your life over the last week. 


\section{Calculation and Interpretation of DLQI}

The DLQI is calculated by summing the score of each question resulting in a maximum of 30 and a minimum of 0 . The higher the score, the more quality of life is impaired. The DLQI is interpreted as follows ${ }^{[39]}$.

\section{DLQI Score Effect on patient's life \\ $0-1 \quad$ no effect at all \\ 2-5 small effect \\ 6-10 moderate effect \\ $11-20 \quad$ very large effect \\ $21-30 \quad$ extremely large effect}

\section{Methods of quality of life assessment}

There are several approaches to design the questionnaires used for QOL measurement ${ }^{[40]}$. In the design and creation of these questionnaires a series of validation steps need to be undertaken. These include the requirement that the information on which the questions are based, comes from patient sources and that the questions are understandable by patients. The questionnaires need to be validated to check that they are answered consistently by patients and that the scores are sensitive to change if the clinical condition changes. There needs to be cross validity with other measures and the internal consistency of the questions needs to be established ${ }^{[41]}$.

\section{Psoriasis Life Stress Inventory (PLSI)}

The psychosocial impact of psoriasis can leads to significant daily stress to the patients which largely arises as a result of cosmetic disfigurement and social stigma ${ }^{[42]}$. The psoriasis related daily stress represents chronic, recurrent low grade stress or hassles that occurs largely as a result of having to live with chronic, relapsing and disfiguring disease. The studies on stress and psoriasis have focused mainly on the role of major stressful life events such as death of loved one, in the onset and exacerbation of disease ${ }^{[43]}$. There is large body of literature that supports the role of stressful life events in the onset and or exacerbation of psoriasis ${ }^{[44]}$.

The PLSI is a 15 -item questionnaire that provides a measure of the daily hassles of psychosocial stress associated with having to cope with everyday events in living with psoriasis. Scores on this scale range from 0 to 45 . It is developed by Finlay et al to measure the psychosocial disability associated with psoriasis ${ }^{[45]}$. The PLSI was developed with the view of obtaining an index of the stress associated with various psoriasis related events. PLSI is scored on a four point scale ranging from zero (not at all) to three (a great deal) as a measure of various psoriasis related events experienced by the patients in the last 4 weeks. The PLSI also permits patients to be classified as a function of their distribution of scores into two groups, which is as follows ${ }^{[46]}$.

- Those patients who react significantly to the stress associated with having psoriasis (score of >10) and

- Those patients who are not significantly affected with having psoriasis-related stress (score of $<10$ ).

In PLSI we measures the 15 items associated with various psoriasis related events and scored on a four point scale, ranging from 0 to 3 , which is tabulated below. 


\section{JMSCR Vol||4||Issue||02||Page 9298-9311||February}

Table.2 Tabular presentation of PLSI ${ }^{[47]}$

\begin{tabular}{|c|c|c|c|c|c|}
\hline \multirow{2}{*}{$\begin{array}{l}\text { S. } \\
\text { No. }\end{array}$} & \multirow[t]{2}{*}{ Items of PLSI } & \multicolumn{4}{|c|}{ Outcome score } \\
\hline & & $\begin{array}{l}\text { Not at } \\
\text { all }=0\end{array}$ & $\begin{array}{l}\text { Slight } \\
\text { degree }=1\end{array}$ & $\begin{array}{l}\text { Moderate } \\
\text { degree }=2\end{array}$ & $\begin{array}{l}\text { Great } \\
\text { deal }=3\end{array}$ \\
\hline 1 & Inconvenienced by shedding of your skin & & & & \\
\hline 2 & Feeling self-conscious among strangers & & & & \\
\hline 3 & $\begin{array}{l}\text { Feeling that you have to set aside a large part of your time } \\
\text { to take care of your psoriasis }\end{array}$ & & & & \\
\hline 4 & $\begin{array}{l}\text { Not going to public place (like swimming pool, health } \\
\text { club, restaurant, etc) when you would have liked to. }\end{array}$ & & & & \\
\hline 5 & $\begin{array}{l}\text { Wearing unattractive or uncomfortable cloths in order to } \\
\text { cover the certain regions of the body. }\end{array}$ & & & & \\
\hline 6 & Having to avoid sunbathing in the company of others. & & & & \\
\hline 7 & Fear of having serious side effects from medical treatment & & & & \\
\hline 8 & People treating you as if your skin condition is contagious & & & & \\
\hline 9 & Avoid social situations & & & & \\
\hline 10 & $\begin{array}{l}\text { Strangers (children or adults) making rude or insensitive } \\
\text { remarks about your appearance }\end{array}$ & & & & \\
\hline 11 & Not enough money to pay medical bills & & & & \\
\hline 12 & $\begin{array}{l}\text { Feeling like an 'outcast' or 'social misfit' a great deal of } \\
\text { time. }\end{array}$ & & & & \\
\hline 13 & People making a conscious effort not to touch you. & & & & \\
\hline 14 & Hairdresser or barber appearing reluctant to cut your hair & & & & \\
\hline 15 & $\begin{array}{l}\text { People implying that your skin condition may be due to } \\
\text { AIDS, leprosy or a venereal disease. }\end{array}$ & & & & \\
\hline
\end{tabular}

\section{Psoriasis disability index (PDI)}

The PDI, developed by Finlay and Coles, concerns the functional life style disabilities caused by psoriasis ${ }^{[48]}$. It contains 15 items with 5 subscales: daily activities, work, personal relations, leisure, and treatment. All items are rated on a 4-point scale, with responses of "not at all", "a little", "a lot", and "very much" scored 0, 1,2 , and 3, respectively. Item scores are summed to yield a total score (range: 0-45) with higher score indicating greater limitations experienced because of psoriasis. Particularly, the PDI has a possible 5 work items, out of which only 3 items need to be responded. Respondents who are working (either full- or part-time) respond to item $6 \mathrm{a}, 7 \mathrm{a}$, and 8 , whereas respondents who are not working respond to items $6 \mathrm{~b}, 7 \mathrm{~b}$, and 8 . When one item of the PDI was not responded, it was scored " 0 ". When two or more items of the PDI were not responded, the questionnaire was excluded from the analysis. ${ }^{[49]}$.
Table.3. Tabular presentation of parameters assessed by PDI. Modified from ${ }^{[49]}$

\begin{tabular}{|l|l|}
\hline Scale & Items \\
\hline Daily activities & 1.House/garden work \\
\hline & 2. Different clothes \\
\hline & 3. Change/wash clothes \\
\hline & 4. Hair dresser problem \\
\hline Work & 5. More baths \\
\hline & 6a. Time off work \\
\hline & 7a. Inhibit work \\
\hline & 6b. Less activity \\
\hline & 7b. Different activity \\
\hline Personal relations & 8. Career affected \\
\hline & 9. Sexual difficulties \\
\hline Leisure & 11. Social relations \\
\hline & 12. Sport difficulties \\
\hline & 13. Communal changing \\
\hline & 14. More smoke/drink \\
\hline Treatment & 15. Home messy/untidy \\
\hline
\end{tabular}

\section{Beer Sheva Psoriasis Severity Score (BPSS)}

The BPSS is a novel tool for the ambulatory assessment of patients with psoriasis. It has 


\section{JMSCR Vol||4||Issue||02||Page 9298-9311||February}

several advantages over the traditional PASI, namely, it is simple and includes items of disease distribution that are lacking in PASI (face, palms and soles, genital area, nails), as well as items of quality of life assessment, global severity indices (assessed by both patients and physicians), and assessment of pruritus. BPSS includes eight items that are recorded by the physician (total severity of the disease, and seven items relating to the physical distribution of the disease) and eight items recorded by the patient (total severity, physical and psychological severity, pruritus, and assessment of involvement in the face, nails, palms and soles, and genital regions). Tabular presentation of different parameters of BPSS are as follows. Modified from ${ }^{[50]}$.

Table 4. Beer Sheva Psoriasis Severity Score (BPSS)

Physician Assessment (Assess the severity of the psoriasis during the last month)

\begin{tabular}{|l|l|l|l|l|l|l|l|l|l|l|l|}
\hline & 0 & 1 & 2 & 3 & 4 & 5 & 6 & 7 & 8 & 9 & 10 \\
\hline & $\begin{array}{l}\text { No } \\
\text { disease }\end{array}$ & $\begin{array}{l}\text { Very } \\
\text { mild }\end{array}$ & & & & & & & & & $\begin{array}{l}\text { Very } \\
\text { severe }\end{array}$ \\
\hline Total severity & & & & & & & & & & & \\
\hline
\end{tabular}

\begin{tabular}{|l|l|l|l|l|}
\hline & 0 & 1 & 2 & 3 \\
\hline & $\begin{array}{l}\text { No } \\
\text { Involvement }\end{array}$ & $\begin{array}{l}\text { Mild } \\
\text { involvement }\end{array}$ & $\begin{array}{l}\text { Moderate } \\
\text { involvement }\end{array}$ & $\begin{array}{l}\text { Severe } \\
\text { involvement }\end{array}$ \\
\hline AREA & & & & \\
\hline Scalp involvement & & & & \\
\hline Face and neck involvement & & & & \\
\hline Upper limbs involvement & & & & \\
\hline Palms involvement & & & & \\
\hline Trunk involvement & & & & \\
\hline Lower limbs involvement & & & & \\
\hline Soles involvement & & & & \\
\hline
\end{tabular}

Patient Assessment (Assess the severity of your psoriasis during the last month)

\begin{tabular}{|l|l|l|l|l|l|l|l|l|l|l|l|}
\hline & 0 & 1 & 2 & 3 & 4 & 5 & 6 & 7 & 8 & 9 & 10 \\
\hline & $\begin{array}{l}\text { No } \\
\text { disease }\end{array}$ & $\begin{array}{l}\text { Very } \\
\text { mild }\end{array}$ & & & & & & & & & $\begin{array}{l}\text { Very } \\
\text { severe }\end{array}$ \\
\hline Total severity & & & & & & & & & & & \\
\hline
\end{tabular}

\begin{tabular}{|l|l|l|l|l|l|l|l|l|l|l|l|}
\hline & 0 \\
\hline
\end{tabular}




\section{Calculation and interpretation of BPSS}

All variables in BPSS are assessed using linear 410 point visual analogue scales. All scores are summed directly, except for the seven items of disease distribution assessed by the physician (which have four-point scales, and are multiplied by 2.5). BPSS ranges from 0 to 160 , with the high scores representing severe disease ${ }^{[51]}$.

\section{The National Psoriasis Foundation Psoriasis Score (NPF-PS)}

It is a composite assessment of investigator and patient characteristics developed to answer the US Food and Drug Administration's criticisms of the PASI and to include skin involvement of Psoriasis in a system that uses ACR and PsA response criteria assessment of joint disease ${ }^{[52]}$. The instrument is based on characteristics felt to be most sensitive [thickness of 2 target lesions and change in body surface area (BSA), from baseline] in assessing Ps, and was also created to provide better cross-study comparisons versus the current instruments.

The NPF-PS includes both objective and subjective assessment. It has 6 endpoints. Two representative target lesions are selected, and the thickness of each is assessed relative to set thickness (induration; $0-1.25 \mathrm{~mm}$ ) on an embossed card. The third element is change in BSA from baseline. There is a PGA and a PtGA as well as an itch assessment. The different parameters of NPF-PS includes ${ }^{[53]}$.

- Induration of representative target lesion A ( 0 to $\geq 1.25 \mathrm{~mm})$

- Induration of representative target lesion B $(0$ to $\geq 1.25 \mathrm{~mm})$

- Body surface area relative to baseline as a percentage (score is $20 \%$ intervals)

- Physician's global assessment (static and defined)

- Patient's global assessment (relative to worst the disease has been ever)

- patient's assessment of itch (defined score $=$ average over $24 \mathrm{~h}$ )
These above six parameters assessed on the 6 point scale ranging from 0 to 5 . Therefore, total outcome score ranges from 0 to 30 .

\section{A brief overview on other outcome measures Physician Global Assessment (PGA)}

In clinical trials, the PGA is recommended by the FDA as an efficacy end point, with its summary score used to measure overall disease severity. The PGA requires physicians to evaluate the severity of plaques for three clinical signs (erythema, induration, and scaling) across the whole body. Although the PGA does not take into account other aspects of psoriasis, such as amount of body surface area affected, pain or pruritus. It is routinely used in clinical trials since it provides a relatively simple assessment of overall disease severity ${ }^{[54]}$.

Typically, the PGA is a 5,6 or 7-point ordinal rating ranging from "clear" to "very severe psoriasis". The PGA can be used to show improvement by a comparison with baseline disease severity (dynamic PGA) or it can be an assessment made at one moment in time (static PGA $)^{[55]}$.

\section{Self-Administered PASI (SAPASI)}

The SAPASI is a structured PASI-like instrument designed for self-assessment of severity by patients ${ }^{[56]}$.

Patients shade in affected areas on a silhouette of a body to estimate body surface area and complete visual analogue scales for the extent of erythema, induration and scaling of their "average" lesion. The investigator uses these data and combines them into a complex score, ranging from 0-72. Psoriasis is defined as ${ }^{[57]}$.

- In remission when SAPASI $=0$

- Mild when SAPASI= 0-3

- Moderate when SAPASI $=0-15$ and

- Severe when SAPASI $=$ more than 15

\section{Simplified PASI (SPASI)}

The SPASI is mathematically derived from the PASI and is developed to measure disease severity 
in simplified way. The SPASI equals the sum of the average erythema, induration and scaling of all the psoriasis lesions and multiplied by an estimate of total percentage body surface areas involved [58].

\section{Psoriasis Assessment Severity Score (PASS)}

The PASS was developed to measure the severity of disease in simpler and faster way than the PASI. The evaluation is divided in two stages, in the first the BSA is determined in percentage and then the general erythema, scaling and induration are assessed on a three-point scale. Finally, the sign scores together with the total percentage BSA are combined in a complex formula, which results into an overall score between 0 and $140^{[59]}$.

\section{Psoriasis Log-Based Area and Severity Index (PLASI) and Psoriasis Exact Area and Severity Index (PEASI)}

The PLASI and PEASI are derived from PASI. These are intended to provide more accurate assessment of improvement. The PLASI uses six BSA groupings (100-46, 46-21, 21-10, 10-5,5-2 and $2-0 \%$ ) with finer partitioning for smaller extents of BSA affected. This is supposed to reduce the error resulting from inaccurate estimation of BSA in patients with less extensive disease and also to increase sensitivity among patients with mild-to-moderate disease in detecting changes in psoriasis severity ${ }^{[60]}$.

The PEASI uses actual BSA percentages instead of an area score for each body area. The PEASI and PLASI have not been validated and are not tested for reliability. Considering responsiveness, the observed percentage change was greater for both the PLASI and the PEASI than with the $\mathrm{PASI}^{[61]}$.

\section{CONCLUSION}

Good clinical psoriasis measures are necessary to measure disease severity and effectiveness of therapies. A large number of clinical outcome measures of psoriasis are used in clinical trials and daily practice. The present review article is aimed to introduce different outcome measures of psoriasis severity and to discuss their importance. Assessing the severity of disease over time is important for optimizing patient care, since it allows for the critical evaluation of individual response to treatment. In addition to assess disease severity, it is often a key aspect of quality care and quality guidelines, which are increasingly important to improve the level of care in the community. It can be concluded that the PASI score is most important and successfully used outcome measure to assess the disease severity and DLQI is most commonly used outcome measure to assess the quality of life in the patients of psoriasis. Overall, none of the instrument was identified as being the best and different situations and clinical states may call for different measures based on the specificity of the clinical condition.

\section{REFERENCES}

1. Farber EM, Nall ML. The natural history of psoriasis in 5,600 patients. Dermatologica. 1974; 148:1-18.

2. Dr Satyapal Singh, Prof. N.P. Rai. Comorbidites with Psoriasis - A Review. Sangyaharan Shodha, 2015; 18(1): 76-85.

3. Stern RS, Nijsten T, Feldman SR, Margolis DJ, Rolstad T: Psoriasis is common, carries a substantial burden even when not extensive, and is associated with widespread treatment dissatisfaction. J Invest Dermatol Symp Proc 2004, 9:136139.

4. Zachariae $\mathrm{R}$, Zachariae $\mathrm{H}$, Blomqvist $\mathrm{K}$, Davidsson S, Molin L, Mørk C, Sigurgeirsson B: Quality of life in 6479 Nordic patients with psoriasis. $\mathrm{Br} \mathrm{J}$ Dermatol 2002, 146:1006-1016.

5. Fredriksson $\mathrm{T}$, Pettersson U: Severe psoriasis-oral treatment with a new retinoid. Dermatologica 1978, 157:238244.

6. Krueger GG, Feldman SR, Camisa C, Duvic M, Elder JT, Gottlieb AB, Koo J, Krueger JG, Lebwohl M, Lowe N, Menter 
A, Morison WL, Prystowsky JH, Shupack JL, Taylor JR, Weinstein GD, Barton TL, Rolstad T, Day RM: Two considerations for patients with psoriasis and their clinicians: What defines mild, moderate, and severe psoriasis? What constitutes aclinically significant improvement when treating psoriasis? J Am Acad Dermatol 2000, 43:281-285.

7. Sampogna F, Sera F, Abeni D: IDI Multipurpose Psoriasis Research on Vital Experiences (IMPROVE) Investigators: Measures of clinical severity, quality of life, and psychological distress in patients with psoriasis: a cluster analysis. J Invest Dermatol 2004, 122:602-607.

8. Chren MM, Weinstock MA: Conceptual issues in measuring the burden ofskin diseases. J Invest Dermatol Symp Proc 2004, 9:97-100.Williams HC: Applying trial evidence back to the patient. Arch Dermatol2003, 139:1195-1200.

9. Chren MM, Lasek RJ, Quinn LM, Mostow EN, Zyzanski SJ: Skindex, a quality of life measure for patients with skin disease: reliability, validity, and responsiveness. $\mathbf{J}$ Invest Dermatol 1996, 107:707-713.

10. Morgan M, McCreedy R, Simpson J, Hay RJ: Dermatology Quality of LifeScales-a measure of the impact of skin disease. Br J Dermatol 1997, 136:202-206.

11. McKenna SP, Cook SA, Whalley D, Doward LC, Richards HL, Griffiths CE, Van Assche D: Development of the PSORI QoL, a psoriasis-specific measure of quality of life designed for use in clinical practice and trials. Br J Dermatol 2003, 149:323-331.

12. Both H, Essink-Bot ML, Busschbach J, Nijsten T: Critical review of genericand dermatology-specific health-related quality of life instruments. J Invest Dermatol 2007, 127:2726-2739.

13. Bronsard V, Paul C, Prey S, Puzenat E, Gourraud PA, Aractingi S, Aubin F, Bagot
M, Cribier B, Joly P, Jullien D, Le Maitre M, Richard-Lallem and MA, Ortonne JP: What are the best outcome measures for assessing quality of life in plaque type psoriasis? A systematic review of the literature. J Eur Acad Dermatol Venereol 2010, 24:17-22.

14. Chren MM: Understanding research about quality of life and other healthoutcomes. J Cutan Med Surg 1999, 3:312-316.

15. Eedy DJ, Griffiths CE, Chalmers RJ et al. (2009) Care of patients with psoriasis: an audit of U.K. services in secondary care. British Journal of Dermatology. 160: $557-$ 64.

16. Finlay AY, Khan GK, Luscombe DK, Salek MS. Validation of Sickness Impact Profile and Psoriasis Disability Index in Psoriasis. Br J Dermatol 1990;123:751-6.

17. Finlay AY, Khan GK. Dermatology Life Quality Index (DLQI) - a simple practical measure for routine clinical use. Clin Exp Dermatol 1994;19:210-16.

18. Gupta MA, Gupta AK. The Psoriasis Life Stress Inventory: a preliminary index of psoriasis-related stress. Acta Derm Venereol 1995;75:240-3.

19. Kirby B, Fortune DG, Bhushan M, et al. The Salford Psoriasis Index: an holistic measure of psoriasis severity. $\mathrm{Br} \mathrm{J}$ Dermatol 2000;142:728-32.

20. Lebwohl M, Christophers E, Langley R, et al. An international, randomized, doubleblind, placebo-controlled phase 3 trial of intramuscular alefacept in patients with chronic plaque psoriasis. Arch Dermatol 2003;139:719-27.

21. Papp K, Bissonnette R, Krueger JG, et al. The treatment of moderate to severe psoriasis with a new anti-CD11a monoclonal antibody. J Am Acad Dermatol 2001;45:665-74.

22. Dr. Singh Satyapal, Prof. Rai NP. Comorbidites with Psoriasis -A Review. Sangyaharan Shodh, 2015; 18(1): 76-85. 
23. See Feldman SR, Krueger GG (2005) Psoriasis assessment tools in clinical trials. Annals of Rheumatic Disease 64 (Suppl. 2): ii65-ii68.

24. Fredriksson T, Pettersson U (1979) Oral treatment of pustulosis-palmo-plantaris with a new retinoid, Ro 10-9359. Dermatologica 158:60-4.

25. Fredriksson T, Pettersson U. Severe psoriasis - oral therapy with a new retinoid. Dermatologica 1978;157: 23844.

26. Satyapal Singh, P S Byadgi, N P Rai. Clinical evaluation of virechan therapy and haridradivati and oil for the management of kitibhkushtha (psoriasis). Int.J.Res. Ayurveda Pharm, 2013, 4(2):207-211.

27. Ochen Schmitt, Gottfried Wozel. The Psoriasis Area and Severity Index Is the Adequate Criterion to Define Severity in Chronic Plaque-Type Psoriasis. Dermatology 2005;210:194-199.

28. Feldman SR. A quantitative definition of severe psoriasis for use in clinical trials. J Dermatol Treat 2004;15:27-9.

29. Jacobson CC, Kimball AB. Rethinking the Psoriasis Area and Severity Index: the impact of area should be increased. $\mathrm{Br} \mathrm{J}$ Dermatol 2004;151:381-7.

30. Sampogna F, Sera F, Abeni D. Measures of clinical severity, quality of life, and psychological distress in patients with psoriasis: a cluster analysis. J Invest Dermatol 2004;122:602-7.

31. Va de Kerkhof PC. The Psoriasis Area and Severity Index and alternative approaches for the assessment of severity: persisting areas of confusion. $\mathrm{Br} \mathrm{J}$ Dermatol 1997;137:661-2.

32. Ashcroft DM, Li Wan PA, Williams HC, Griffiths CE. Quality of life measures in psoriasis: a critical appraisal of their quality. J Clin Pharm Ther 1998;23:391-8.

33. Ashcroft DM, Wan Po AL, Williams HC, Griffiths CE. Clinical measures of disease severity and outcome in psoriasis: a critical appraisal of their quality. $\mathrm{Br} \mathbf{J}$ Dermatol 1999;141:185-91.

34. Monali J Bhosle1, Amit Kulkarni, Steven $\mathrm{R}$ Feldman and Rajesh Balkrishnan. Quality of life in patients with psoriasis. Health and Quality of Life Outcomes 2006, 4:35.

35. Finlay AY, Khan GK. Dermatology Life Quality Index (DLQI) - a simple practical measure for routine clinical use. Clin Exp Dermatol. 1994;19:210-6.

36. Lewis V, Finlay AY. 10 years' experience of the Dermatology Life Quality Index (DLQI). J Investig Dermatol Sympproc 2004; 9: 169-180.

37. Basra MK, Fenech R, Gatt RM, Salek MS, Finlay AY. The Dermatology Life Quality Index 1994-2007: a comprehensive review of validation data and clinical results. br $\mathbf{J}$ Dermatol 2008; 159: 997-1035.].

38. Andrew Y Finlay. Quality of Life Indices. Indian J Dermatol Venereol Leprol, 2004;70:143-48.

39. Hongbo Y, Thomas CL, Harrison MA, Salek MS and Finlay AY. Translating the science of quality of life into practice: What do dermatology life quality index scores mean? J Invest Dermatol 2005; 125:659-64.

40. Finlay AY. Quality of life measurement in dermatology: Apractical guide. $\mathrm{Br} \mathrm{J}$ Dermatol 1997;136:305-14.

41. Finlay AY. Quality of Life Indices. Indian J Dermatol Venereol Leprol 2004;70:14348.

42. Ramsay B, O Regan M. A survey of social and psychological effect of psoriasis. Br J Dermatol, 1988: 118: 195-201.

43. Gupta Ma, Gupta AK Heberman HF. Psoriasis and psychiatry: an update. Gen hosp psychiatry, 1987; 9: 157-166.

44. Satyapalsingh, J.S. Tripathi, N.P. Rai. An overview of Ayurvedic \& contemporary approaches to Psychodermatology. The 
Journal of Phytopharmacology 2014; 3(4): 286-299.

45. Finlay AY, Kelley SE. psoriasis- an index of disability. Clinical expdermatol, 1987; 12: 8-11.

46. Finlay AY, Kelley SE. psoriasis- an index of disability. Clinical expdermatol, 1987; 12: 8-11.

47. Madulika A gupta, Aditya K Gupta. The psoriasis life stress inventory: a preliminary index of psoriasis related stress. Actadermvenereol (stockh), 1995; 75:240-243.

48. Finlay AY, Coles EC: The effect of severe psoriasis on the quality of life of 369 patients. Br J Dermatol 1995, 132:236244.

49. Zehui He, Chuanjian Lu, Aihua Ou, Jiqian Fang, Dongmei Wang, Jingwen Deng, Zhongzhao Zhang and Jingjie Yu. Reliability and validity of the Chinese version of the Psoriasis Disability Index (PDI) in Chinese patients with psoriasis. Health and Quality of Life Outcomes 2012, 10:37; 1-7.

50. Arnon D. Cohen, Dina Van-Dijk, Lechaim Naggan and Daniel A. Vardy. Factor Analysis of the Beer Sheva Psoriasis Severity Score (BPSS). MAJ 2008;10:419-423.

51. Cohen AD, Van-Dijk D, Naggan L, Vardy DA. Effectiveness of climatotherapy at the Dead Sea for Israeli patients with psoriasis vulgaris. A community oriented study introducing "Beer Sheva Psoriasis Severity Score." J Dermatol Treat 2005;16:308.

52. Carlin CS, Callis KP, Krueger GG. Efficacy of acitretin and commercial tanning bed therapy for psoriasis. Arch Dermatol2003; 139:459-64.

53. Dafna D. Gladman, Philip J. Mease, Gerald Krueger, Désirée M.F.M. Van Der Heidje, Christian Antoni, Philip S. Helliwell, Arthur F. Kavanaugh, Peter Nash, Christopher T. Ritchlin, C. Vibeke
Strand, And William Taylor. Outcome Measures in Psoriatic Arthritis. The Journal of Rheumatology 2005; 32(11): 2262-2269.

54. Paul C, Bushmakin AG, Cappelleri JC, Mallbris L, Mamolo C. Do Patients and Physicians Agree in Their Assessment of the Severity of Psoriasis? Insights from Tofacitinib Phase 3 Clinical Trials. . J Dermatolog Clin Res, 2015; 3(3): 1048.

55. Gottlieb AB, Chaudhari U, Baker DG et al. (2003) The National Psoriasis Foundation Psoriasis Score (NPF-PS) system versus the Psoriasis Area Severity Index (PASI) and Physician's Global Assessment (PGA): a comparison. J Drugs Dermatol 2:260-6.

56. Fleischer AB Jr, Rapp SR, Reboussin DM et al. (1994) Patient measurement of psoriasis disease severity with a structured instrument. J Invest Dermatol, 102:967-9.

57. Fleischer AB Jr, Feldman SR, Rapp SR et al. (1996) Disease severity measures in a population of psoriasis patients: the symptoms of psoriasis correlate with selfadministered psoriasis area severity index scores. J Invest Dermatol 107:26-9.

58. Louden BA, Pearce DJ, Lang W et al. (2004) A simplified psoriasis area severity index (SPASI) for rating psoriasis severity in clinic patients. Dermatol Online J 10:7.

59. Harari M, Shani J, Hristakieva E et al. (2000) Clinical evaluation of a more rapid and sensitive Psoriasis Assessment Severity Score (PASS), and its comparison with the classic method of Psoriasis Area and Severity Index (PASI), before and after climatotherapy at the Dead-Sea. Int J Dermatol 39:913-8.]

60. Phyllis I. Spuls, Lidian L.A. Lecluse, Marie-Louise N.F. Poulsen, Jan D. Bos, Robert S. Stern, Tamar Nijsten. How Good Are Clinical Severity and Outcome Measuresfor Psoriasis?: Quantitative Evaluation in a SystematicReview. Journal 
of Investigative Dermatology, (2010); 130,: 933-943.

61. Jacobson CC, Kimball AB (2004) Rethinking the psoriasis area and severityindex: the impact of area should be increased. Br J Dermatol 151:38,1-7. 